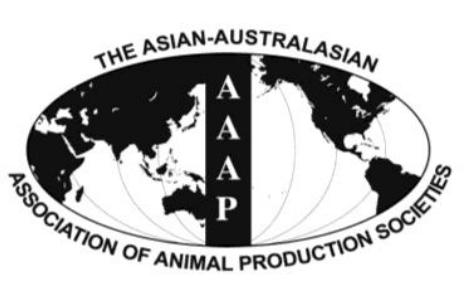

Open Access

Asian Australas. J. Anim. Sci.

Vol. 28, No. 3 : 323-327 March 2015

http://dx.doi.org/10.5713/ajas.14.0410

www.ajas.info

pISSN 1011-2367 elSSN 1976-5517

\title{
Asymmetries in Chickens from Lines Selected and Relaxed for High or Low Antibody Titers to Sheep Red Blood Cells
}

\author{
Yunjie Tu* and P. B. Siegel ${ }^{1}$ \\ Poultry Institute, Chinese Academy of Agricultural Sciences, Yangzhou, Jiangsu 225125, China
}

\begin{abstract}
Wattle length, width, and area were measured to classify bilateral asymmetries in four lines of chickens. The lines were the S26 generation of White Leghorns selected for high (HAS) or low (LAS) response to sheep red blood cells and sublines in which selection had been relaxed for three generations (high antibody relaxed [HAR] and low antibody relaxed [LAR]). Antibody titers (AB) were greater for HAS than for HAR with both greater than for LAS and LAR which while different for males did not differ for females. The low antibody lines were heavier and reached sexual maturity at younger age than the high antibody lines. In general, wattle length, width, and area were greater in the low than high antibody lines. In 24 comparisons for bilaterality 18 exhibited fluctuating asymmetry and 6 exhibited directional asymmetry with 5 of the 6 being for wattle length. There was not a clear pattern for changes in degree of asymmetry when selection was relaxed for 3 generations. For females, the relative asymmetry (RA) of wattle area was larger $(\mathrm{p} \leq 0.05)$ for HAR than for LAR and not different from the selected lines and relaxed lines. There were no differences among lines for RA of wattle length and width of females and wattle length, width, and area of males. (Key Words: Chicken, Asymmetry, Selection, Wattle, Stress)
\end{abstract}

\section{INTRODUCTION}

Bilateral asymmetry, the deviation of part of an organism from perfect symmetry, can be categorized as fluctuating asymmetry (FA), directional asymmetry (DA), or anti-symmetry (AS) (Van Valen, 1962). Each of these categories is characterized by a different combination of the mean and the distribution of left minus right. The degree of asymmetry in bilateral morphological characters may reflect responses to genetic and environmental stressors and interactions between them (Yang et al., 1997; Campo et al., 2007). Intensive directional selection for a trait can increase developmental instability and impose selection against genetic modifiers that reduce the development of extreme phenotypes in a range of species including chickens

\footnotetext{
* Corresponding Author: Yunjie Tu. Tel: +86-514-86587763, Fax: +86-514-86587763, E-mail: tyj3030@126.com

1 Department of Animal and Poultry Sciences, Virginia Polytechnic Institute and State University, Blacksburg, VA 24061, USA.

Submitted Jun. 3, 2014; Revised Aug. 14, 2014; Accepted Sept. 4, 2014
}

(Parsons, 1992; Yang and Siegel, 1998). Age and sex also can influence asymmetries for toe, leg, wing, and feather length, as well as wattle area of chickens (Campo et al., 2005 ; 2012). The relationship between size and asymmetry of bilateral traits has been used as a predictor of growth, fecundity, and survival of different species including chickens (Møller et al., 1995; Campo et al., 2007; Prieto et al., 2011).

Long-term artificial selection for certain traits can alter the dynamic involving the acquisition and allocation of resources (Yang et al., 1997; Zhao et al., 2012). Thus, artificial selection for a specific trait may result in correlated responses in unselected traits. Selection for immune responses in chickens can result in correlated responses in production and disease-related traits (Pinardvan der Laan et al., 1998). Long-term bidirectional selection for high and low antibody response to response to sheep red blood cells (SRBC) titers in chickens has led to a considerable phenotypic divergence between the selected lines with plateauing in the low line (Zhao et al., 2012). Bilateral asymmetries were lower for crosses of lines 
divergently selected for antibody responses to SRBC than for their parental lines which, like heterosis, reflected their greater biological and developmental stability and fitness (Yang and Siegel, 1998).

The purpose of the experiment reported here was designed to measure the asymmetry of wattle characteristics and related growth and reproductive traits in lines of chickens selected for high and low antibodies to SRBC and in sublines where selection was relaxed.

\section{MATERIALS AND METHODS}

\section{Populations}

The White Leghorn chickens used in this experiment were from lines selected 26 generations for high antibody (HAS) and low antibody (LAS) response $5 \mathrm{~d}$ after a single intravenous injection of $0.1 \mathrm{~mL}$ of a $0.25 \%$ suspension of SRBC antigen administrated between 41 and $51 \mathrm{~d}$ of age (Kuehn et al., 2006). Beginning in generation 23, HAS and LAS individuals were randomly chosen to produce sublines in which selection was relaxed. Those sublines, high antibody relaxed (HAR) and low antibody relaxed (LAR) had been relaxed for three generations and were contemporaries with the selected lines. Details about the selection procedures and husbandry have been described previously (Kuehn et al., 2006; Zhao et al., 2012). For the chickens used in this experiment their antibody titers (AB) were obtained as typical for this selection experiment and described at the beginning of this paragraph.

They were hatched at the first Tuesday in March, vaccinated against Marek's disease, and reared as contemporaries in floor pens until $18 \mathrm{wk}$ of age, when they were transferred to individual cages. The same starter $(20 \%$ crude protein $[\mathrm{CP}]$ and 2,685 kcal of metabolizable energy $[\mathrm{ME}] / \mathrm{kg}$ ), grower (14\% CP and 2,827 of kcal ME/kg), and layer $(16.1 \% \mathrm{CP}$ and $2,752 \mathrm{kcal}$ of $\mathrm{ME} / \mathrm{kg}$ ) diets were fed ad libitum in mash form throughout.

\section{Traits measured}

Fifteen males and 15 females randomly chosen from lines HAS and LAS and 10 males and 15 females randomly chosen from lines HAR and LAR were used in this experiment. At $32 \mathrm{wk}$ of age, the left and right wattle length and width (spread flat) were measured. Left and right measurements were made by the same two individuals (a holder and a measurer) during the same session with ordering at random. All lengths and widths were measured in $\mathrm{mm}(0.1)$ using a digital caliper. Wattle areas $\left(\mathrm{mm}^{2}\right)$ were calculated as length times width. For females, the length of comb (from dent in front to end of blade) and height of comb (from flat of head to end of the highest point above the eye) was also measured in $\mathrm{mm}(0.1)$. There were three categories for left minus right $(\mathrm{L}-\mathrm{R})$ bilateral differences
(Yang et al., 1997), which were mean zero and normal distribution for FA, mean not zero and normal distribution for DA, and mean zero with a distribution that was not normal for AS.

The $\mathrm{AB}$ was measured as described in the populations section of this paper. Production data for females included age at the first egg (AFE), body weight at $4 \mathrm{wk}$ (BW4) and $24 \mathrm{wk}$ (BW24), and at first egg (BWFE), as well as \% hen day egg production to 275 days of age. For males, body weight at 32 wk (BW32) was measured. Body weights were measured to the nearest $\mathrm{g}$. at $4 \mathrm{wk}$ and at older ages.

\section{Statistical analyses}

Data for comparisons involving traits of the 4 lines were analyzed by one way analysis of variance among and within lines using SAS 9.2 for males and for females (Institute, Inc., Cary, NC, USA). Each signed (+ or -) bilateral asymmetry (left minus right) was tested for normality with mean zero by the Shapiro-Wilk statistic and one sample ttest using SAS 9.2 (SAS Institute, Inc., Cary, NC, USA). The AFE, BWFE, BW24, and BW32 were transformed into $\log _{10}$ before analyses because means and variances were correlated. The Tukey's test was used to separate means. Differences were considered significant at $\mathrm{p} \leq 0.05$.

\section{RESULTS}

\section{Antibody titers, growth, reproductive traits, wattle length, width and area}

For both males and females $A B$ was greater $(\mathrm{p} \leq 0.05)$ for the high than low lines (Table 1). Three generations of relaxed selection in the high line resulted in lower $A B$ $(p \leq 0.05)$ than in selected line in both sexes. In the low line there was an increase of $\mathrm{AB}$ in the relaxed line with difference significant $(\mathrm{p} \leq 0.05)$ in males but not in females. Low antibody lines were consistently heavier $(p \leq 0.05)$ than high lines and in general matured at younger ages. Hen-day egg production was lower $(\mathrm{p} \leq 0.05)$ for HAS than the other 3 lines, which did not differ.

For females, the length of the left wattle was longer $(p \leq 0.05)$ for LAS than for HAS with the relaxed lines intermediate and not different from each other or the selected lines (Table 1). In contrast, there were no differences among lines for length of the right wattle. For wattle width, the pattern among lines was essentially the opposite of that for length. Namely, there were no differences among lines for left wattle width, while for right the pattern was consistent with that observed for left wattle length. For wattle area the general pattern was for larger $(\mathrm{p} \leq 0.05)$ values for the low than the high lines.

For males, there were differences $(\mathrm{p} \leq 0.05)$ among lines for left wattle length with LAS $>$ LAR $>$ HAR $>$ HAS. For right wattle length the pattern among lines was consistent 
Table 1. Means \pm SE of traits for females and males by line ${ }^{1}$

\begin{tabular}{|c|c|c|c|c|c|}
\hline Sex & Traits & HAS & HAR & LAR & LAS \\
\hline \multicolumn{6}{|c|}{ Females } \\
\hline & $\mathrm{AB}$ & $10.7 \pm 0.4^{\mathrm{a}}$ & $8.4 \pm 0.7^{\mathrm{b}}$ & $3.3 \pm 0.4^{\mathrm{c}}$ & $2.2 \pm 0.3^{\mathrm{c}}$ \\
\hline & BW4 (g) & $154.4 \pm 3.3^{\mathrm{b}}$ & $161.9 \pm 4.6^{\mathrm{b}}$ & $192.4 \pm 4.0^{\mathrm{a}}$ & $183.2 \pm 3.4^{\mathrm{a}}$ \\
\hline & BWFE (g) & $1,361.4 \pm 66.3^{\mathrm{ab}}$ & $1,328.1 \pm 83.4^{\mathrm{b}}$ & $1,416.7 \pm 141.7^{\mathrm{a}}$ & $1,416.7 \pm 125.7^{\mathrm{a}}$ \\
\hline & BW24 (g) & $1,294.0 \pm 114.2^{\mathrm{b}}$ & $1,240.0 \pm 90.5^{b}$ & $1,402.7 \pm 120.2^{\mathrm{a}}$ & $1,402.7 \pm 126.9^{\mathrm{a}}$ \\
\hline & $\operatorname{AFE}(d)$ & $177.1 \pm 11.6^{\mathrm{ab}}$ & $180.9 \pm 10.4^{\mathrm{a}}$ & $167.7 \pm 10.2^{\mathrm{bc}}$ & $172.1 \pm 6.6^{\mathrm{c}}$ \\
\hline & $\mathrm{EP}(\%)$ & $74.0 \pm 2.1^{\mathrm{b}}$ & $78.1 \pm 0.9^{a}$ & $79.4 \pm 0.7^{\mathrm{a}}$ & $79.6 \pm 1.0^{\mathrm{a}}$ \\
\hline & Wattle length, left (mm) & $31.27 \pm 0.61^{\mathrm{b}}$ & $32.00 \pm 0.84^{\mathrm{ab}}$ & $32.07 \pm 0.69^{\mathrm{ab}}$ & $33.73 \pm 0.90^{\mathrm{a}}$ \\
\hline & Wattle length, right $(\mathrm{mm})$ & $32.60 \pm 0.70$ & $34.56 \pm 0.99$ & $33.13 \pm 0.87$ & $35.40 \pm 1.12$ \\
\hline & Wattle width, left (mm) & $29.80 \pm 0.62$ & $29.56 \pm 0.86$ & $30.93 \pm 0.75$ & $31.93 \pm 0.85$ \\
\hline & Wattle width, right (mm) & $28.13 \pm 0.60^{b}$ & $29.12 \pm 0.63^{\mathrm{ab}}$ & $30.67 \pm 0.39^{\mathrm{a}}$ & $30.80 \pm 1.12^{\mathrm{a}}$ \\
\hline & Wattle area, left $\left(\mathrm{mm}^{2}\right)$ & $934.20 \pm 31.16^{\mathrm{b}}$ & $948.63 \pm 40.04^{\mathrm{b}}$ & $995.53 \pm 38.60^{\mathrm{a}}$ & $1,083.20 \pm 49.67^{\mathrm{a}}$ \\
\hline & Wattle area, right $\left(\mathrm{mm}^{2}\right)$ & $918.07 \pm 30.09^{\mathrm{ab}}$ & $1,011.75 \pm 44.50^{\mathrm{b}}$ & $1,017.60 \pm 33.11^{\mathrm{ab}}$ & $1,099.60 \pm 64.94^{\mathrm{a}}$ \\
\hline \multicolumn{6}{|c|}{ Males } \\
\hline & $\mathrm{AB}$ & $11.8 \pm 0.4^{\mathrm{a}}$ & $8.9 \pm 0.6^{\mathrm{b}}$ & $2.5 \pm 0.2^{\mathrm{c}}$ & $1.2 \pm 0.1^{\mathrm{d}}$ \\
\hline & BW32 (g) & $1,766.0 \pm 148.3^{b}$ & $1762.0 \pm 156.2^{\mathrm{b}}$ & $1,807.0 \pm 125.0^{\mathrm{a}}$ & $1,898.0 \pm 119.2^{\mathrm{a}}$ \\
\hline & Wattle length, left (mm) & $71.40 \pm 1.98^{\mathrm{d}}$ & $78.00 \pm 2.81^{\mathrm{c}}$ & $83.80 \pm 1.82^{\mathrm{b}}$ & $92.07 \pm 1.43^{\mathrm{a}}$ \\
\hline & Wattle length, right (mm) & $75.40 \pm 2.08^{\mathrm{c}}$ & $83.90 \pm 3.17^{\mathrm{b}}$ & $89.00 \pm 1.73^{\mathrm{ab}}$ & $91.87 \pm 1.94^{\mathrm{a}}$ \\
\hline & Wattle width, left (mm) & $65.33 \pm 1.67^{\mathrm{c}}$ & $68.70 \pm 2.22^{\mathrm{bc}}$ & $72.70 \pm 2.13^{\mathrm{ab}}$ & $77.60 \pm 1.93^{\mathrm{a}}$ \\
\hline & Wattle width, right (mm) & $63.80 \pm 1.35^{\mathrm{c}}$ & $64.60 \pm 1.82^{\mathrm{c}}$ & $72.60 \pm 1.51^{\mathrm{a}}$ & $78.27 \pm 1.97^{\mathrm{b}}$ \\
\hline & Wattle area, left $\left(\mathrm{mm}^{2}\right)$ & $4,668.20 \pm 184.17^{\mathrm{c}}$ & $5,397.00 \pm 336.62^{\mathrm{bc}}$ & $6,106.30 \pm 261.00^{\mathrm{b}}$ & $7,172.40 \pm 276.58^{a}$ \\
\hline & Wattle area, right $\left(\mathrm{mm}^{2}\right)$ & $4,830.27 \pm 202.77^{b}$ & $5,459 \cdot 10 \pm 342 \cdot 16^{\mathrm{b}}$ & $6,473.00 \pm 225.09^{a}$ & $7,216.67 \pm 311.32^{\mathrm{a}}$ \\
\hline
\end{tabular}

SE, standard error; AB, antibody titer; BWFE, body weight at the first egg; BW4, 4-week body weight; BW24, 24-week body weight; AFE, age at the first egg; EP\%, \% hen-day egg production; BW32, 32-week body weight; SRBC, sheep red blood cells.

${ }^{1}$ HAS, selected 26 generations for high antibody response to SRBC; LAS, selected 26 generations for low antibody response to SRBC; HAR and LAR, sublines of HAS and LAS, respectively, where selection was relaxed for 3 generations.

${ }^{\mathrm{a}-\mathrm{d}}$ Means in a row with different superscripts differ significantly $(\mathrm{p} \leq 0.05)$.

with that for the left wattle, but not as distinct. Left wattle width was greater $(\mathrm{p} \leq 0.05)$ for the low than for the high lines, and consistent within the respective high and low lines. For right wattle width, it was LAR $>$ LAS $>$ HAS, HAR. Left and right wattle areas was largest for LAS, smallest for HAS $(p \leq 0.05)$ with relaxed lines intermediate to the selected lines.

The results of correlation analysis between wattle length, wattle width and wattle area were as follows. Wattle area was significantly positive correlated with both wattle length and wattle width $(\mathrm{p} \leq 0.01)$, and the correlation coefficient was 0.913 and 0.914 , respectively. The correlation between wattle length and wattle width was $0.680(\mathrm{p} \leq 0.01)$.

\section{Asymmetry and relative asymmetry}

Of 24 comparisons for asymmetries there were 6 for DA, 18 for FA and none for AS. The type of asymmetry for wattle length differed according to lines (Table 2) with HAS and LAR females exhibiting FA and line HAR and LAS females exhibiting DA. For males there was DA for line HAS, HAR, and FA for LAR and LAS. In all cases DA was negative $(\mathrm{L}<\mathrm{R})$. The asymmetry for wattle width was FA, the exception being DA for HAS females. When considered for wattle area per se, regardless of sex or line all asymmetries was FA.

For females, the relative asymmetry (RA) of wattle area was larger $(\mathrm{p} \leq 0.05)$ for HAR than for LAR and not different from the selected lines and relaxed lines (Table 2). There were no differences among lines for RA of wattle length, width of females and wattle length, width, and area of males.

\section{DISCUSSION}

Low antibody selected and relaxed lines had lower AB, were heavier than high lines, and matured at younger ages, results consistent with long-term reports of selection for these lines (Zhao et al., 2012). Percent egg production increased when selection was relaxed in the high lines so that HAR did not differ from that of LAR and LAS. This suggests a general increase in reproductive fitness concomitant to relaxation of selection for high antibody response. This was because over-production of antibodies had a negative effect on fitness relative to other traits. In a comparison with the ISA Babcok breeders Inc. (Ithaca, NY, USA), Warren cross chickens (brown-egg layers) divergently selected for antibody level to SRBC (Verhulst et al., 1999), the line selected for low immune function had 
Table 2. Means \pm SE of asymmetry ${ }^{1}$ and $\mathrm{RA}^{2}$ for males and females by line ${ }^{3}$

\begin{tabular}{llcccc}
\hline Sex & \multicolumn{1}{c}{ Traits } & HAS & HAR & LAR & LAS \\
\hline Females & & & & \\
& Asymmetry of wattle length & $-1.33 \pm 0.71 \mathrm{FA}$ & $-2.56 \pm 0.90 \mathrm{DA}$ & $-1.07 \pm 0.69 \mathrm{FA}$ & $-1.67 \pm 0.78 \mathrm{DA}$ \\
& Asymmetry of wattle width & $1.67 \pm 0.63 \mathrm{DA}$ & $0.44 \pm 0.63 \mathrm{FA}$ & $0.27 \pm 0.51 \mathrm{FA}$ & $1.13 \pm 0.90 \mathrm{FA}$ \\
& Asymmetry of wattle area & $-16.13 \pm 27.54 \mathrm{FA}$ & $-63.13 \pm 35.17 \mathrm{FA}$ & $-22.07 \pm 24.38 \mathrm{FA}$ & $-16.40 \pm 35.54 \mathrm{FA}$ \\
& RA of wattle length $^{4}$ & $7.07 \pm 1.61$ & $10.61 \pm 1.93$ & $6.56 \pm 1.48$ & $6.84 \pm 1.59$ \\
& RA of wattle width & $7.60 \pm 1.73$ & $6.65 \pm 1.33$ & $4.71 \pm 1.13$ & $8.29 \pm 1.97$ \\
& RA of wattle area & $9.06 \pm 1.59^{\mathrm{ab}}$ & $14.19 \pm 1.55^{\mathrm{a}}$ & $7.14 \pm 1.98^{\mathrm{b}}$ & $9.02 \pm 1.95^{\mathrm{ab}}$ \\
& & & & \\
& & & & \\
& Asymmetry of wattle length & $-4.00 \pm 1.33^{\mathrm{ab}} \mathrm{DA}$ & $-5.90 \pm 0.92^{\mathrm{b}} \mathrm{DA}$ & $-5.20 \pm 1.69^{\mathrm{b}} \mathrm{DA}$ & $0.20 \pm 1.64^{\mathrm{a}} \mathrm{FA}$ \\
& Asymmetry of wattle width & $1.53 \pm 1.15^{\mathrm{ab}} \mathrm{FA}$ & $4.10 \pm 1.88^{\mathrm{a}} \mathrm{FA}$ & $0.10 \pm 1.86^{\mathrm{ab}} \mathrm{FA}$ & $-0.67 \pm 1.12^{\mathrm{b}} \mathrm{FA}$ \\
& Asymmetry of wattle area & $-162.07 \pm 94.51 \mathrm{FA}$ & $-62.10 \pm 185.21 \mathrm{FA}$ & $-366.70 \pm 194.18 \mathrm{FA}$ & $-44.27 \pm 159.42 \mathrm{FA}$ \\
& RA of wattle length & $7.13 \pm 1.35$ & $7.24 \pm 1.06$ & $7.25 \pm 1.57$ & $5.35 \pm 1.14$ \\
& RA of wattle width & $5.73 \pm 1.12$ & $8.60 \pm 1.68$ & $6.03 \pm 1.42$ & $3.84 \pm 0.94$ \\
& RA of wattle area & $6.60 \pm 1.24$ & $7.07 \pm 2.14$ & $9.28 \pm 2.08$ & $6.22 \pm 1.22$ \\
\hline
\end{tabular}

SE, standard error; SRBC, sheep red blood cells.

${ }^{1} \mathrm{FA}$, fluctuating asymmetry; DA, directional asymmetry. Asymmetry $=|\mathrm{L}-\mathrm{R}|$. Wattle area $=$ wattle length $\times$ wattle width.

${ }^{2} \mathrm{RA}$, relative asymmetry, $\left.\mathrm{RA}=(\mid \mathrm{L}-\mathrm{R} / /[(\mathrm{L}+\mathrm{R}) / 2)]\right) \times 100$.

${ }^{3}$ HAS, selected 26 generations for high antibody response to SRBC; LAS, selected 26 generations for low antibody response to SRBC; HAR and LAR, sublines of HAS and LAS, respectively, where selection was relaxed for 3 generations.

${ }^{\mathrm{a}-\mathrm{d}}$ Means in a row with different superscripts differ significantly ( $\left.\mathrm{p} \leq 0.05\right)$.

larger combs than high-selected line. Consistent with their results, we found that generally wattle length, width, and area for the low antibody lines were greater than for the high antibody lines. The central point of Verhulst et al. (1999) was that a tradeoff exists between sexual ornamentation and immune function. The relationship may reflect greater fitness and is consistent with the heterotic effect reported in our lines (Yang and Siegel, 1998). These results support the idea that a tradeoff with immune function may constrain the expression of secondary sexual ornaments.

Morever, Campo et al. (2005) and Buijs et al. (2012) suggested that DA may be less associated with developmental stability than FA in chickens. Our results were consistent with these observations for wattle size and that 18 of 24 comparisons for asymmetry were FA. Developmental instability may provide reliable information about the ability of individuals and populations to cope with their environment given their genetic setup. There is an increasing interest in the use of various measures of developmental instability to understand a wide range of ecological and evolutionary problems (Møller and Swaddle, 1997; Thornhill and Møller, 1997; Rauw, 2009). Some researches found that FA related to fitness (Møller, 1997; 1999). It has been proposed that RA could be valid candidates for measuring developmental stability in chickens (Yang et al., 1997). Our results found that RA of wattle area was larger for HAR than for LAR and not different from the selected lines and relaxed lines for females. The RA of wattle length, width for females and wattle length, width, and area for males were consistent with each other among lines.

\section{ACKNOWLEDGMENTS}

The current research was funded in part by the National Natural Science Foundation of China (31402032).

\section{REFERENCES}

Buijs, S., E. Van Poucke, S. Van Dongen, L. Lens, J. Baert, and F. A. M. Tuyttens. 2012. The influence of stocking density on broiler chicken bone quality and fluctuating asymmetry. Poult. Sci. 91:1759-1767.

Campo, J. L., M. G. Gil, S. G. Davila, and I. Munoz. 2005. Estimation of heritability for fluctuating asymmetry in chickens by restricted maximum likelihood. Effects of age and sex. Poult. Sci. 84:1689-1697.

Campo, J. L., M. G. Gil, S. G. Davila, and I. Munoz. 2007. Genetic and phenotypic correlation between fluctuating asymmetry and two measurements of fear and stress in chickens. Appl. Anim. Behav. Sci. 102:53-64.

Campo, J. L., S. G. Davila, M. T. Prieto, and M. G. Gil. 2012. Associations among fluctuating asymmetry, tonic immobility duration, and flight distance or ease of capture in chickens. Poult. Sci. 91:1575-1581.

Kuehn, L. A., S. E. Price, C. F. Honaker, and P. B. Siegel. 2006. Antibody response of chickens to sheep red blood cells: Crosses among divergently selected lines and relaxed sublines. Poult. Sci. 85:1338-1341.

Møller, A. P., G. S. Sanotra, and K. S. Vestergaard. 1995. Developmental stability in relation to population density and breed of chickens gallus gallus. Poult. Sci. 74:1761-1771.

Møller, A. P. 1997. Developmental stability and fitness: A review. 
Am. Nat. 149:916-932.

Møller, A. P. 1999. Developmental stability is related to fitness. Am. Nat. 153:556-560.

Møller, A. P. and R. Thornhill. 1997. A meta-analysis of the heritability of developmental stability. J. Evol. Biol. 10:1-16.

Møller, A. P. and J. P. Swaddle. 1997. Asymmetry, Developmental Stability, and Evolution. Oxford University Press, Oxford, UK.

Parsons, P. A. 1992. Fluctuating asymmetry: A biological monitor of environmental and genomic stress. Heredity 68:361-364.

Pinard-van der Laan, M.-H., P. Siegel, and S. Lamont. 1998. Lessons from selection experiments on immune response in the chicken. Poult. Avian Biol. Rev. 9:125-141.

Prieto, M. T., J. L. Campo, and J. Santiago-Moreno. 2011. Relationship among fluctuating asymmetry, morphological traits, and sperm quality in layers. Poult. Sci. 90:2845-2854.

Rauw, W. M. 2009. Resource Allocation Theory Applied to Farm Animal Production. CABI, Cambridge, MA, USA.
Thornhill, R. and A. P. Møller. 1997. Developmental stability, disease and medicine. Biol. Rev. Camb. Pilos. Soc. 72:497-548.

Van Valen, L. 1962. A study of fluctuating asymmetry. Evolution $16: 125-142$.

Verhulst, S., S. J. Dieleman, and H. K. Parmentier. 1999. A tradeoff between immunocompetence and sexual ornamentation in domestic fowl. Proc. Natl. Acad. Sci. USA. 96:4478-4481.

Yang, A., E. A. Dunnington, and P. B. Siegel. 1997. Developmental stability in stocks of White Leghorn chickens. Poult. Sci. 76:1632-1636.

Yang, A. and P. B. Siegel. 1998. Asymmetries and heterosis of bilateral traits in parental lines of chickens and their $F_{1}$ crosses. J. Anim. Breed. Genet. 115:105-111.

Zhao, X. L., C. F. Honaker, and P. B. Siegel. 2012. Phenotypic responses of chickens to long-term selection for high or low antibody titers to sheep red blood cells. Poult. Sci. 91:10471056. 